\title{
Association between mortality and indicators of traffic-related air pollution in the Netherlands: a cohort study
}

Citation for published version (APA):

Hoek, G., Brunekreef, B., Goldbohm, R. A., Fischer, P., \& van den Brandt, P. A. (2002). Association between mortality and indicators of traffic-related air pollution in the Netherlands: a cohort study. Lancet, 360(9341), 1203-1209. https://doi.org/10.1016/S0140-6736(02)11280-3

Document status and date:

Published: 01/01/2002

DOI:

10.1016/S0140-6736(02)11280-3

Document Version:

Publisher's PDF, also known as Version of record

Please check the document version of this publication:

- A submitted manuscript is the version of the article upon submission and before peer-review. There can be important differences between the submitted version and the official published version of record.

People interested in the research are advised to contact the author for the final version of the publication, or visit the DOI to the publisher's website.

- The final author version and the galley proof are versions of the publication after peer review.

- The final published version features the final layout of the paper including the volume, issue and page numbers.

Link to publication

\footnotetext{
General rights rights.

- You may freely distribute the URL identifying the publication in the public portal. please follow below link for the End User Agreement:

www.umlib.nl/taverne-license

Take down policy

If you believe that this document breaches copyright please contact us at:

repository@maastrichtuniversity.nl

providing details and we will investigate your claim.
}

Copyright and moral rights for the publications made accessible in the public portal are retained by the authors and/or other copyright owners and it is a condition of accessing publications that users recognise and abide by the legal requirements associated with these

- Users may download and print one copy of any publication from the public portal for the purpose of private study or research.

- You may not further distribute the material or use it for any profit-making activity or commercial gain

If the publication is distributed under the terms of Article $25 \mathrm{fa}$ of the Dutch Copyright Act, indicated by the "Taverne" license above, 


\section{@ Association between mortality and indicators of traffic-related air pollution in the Netherlands: a cohort study}

Gerard Hoek, Bert Brunekreef, Sandra Goldbohm, Paul Fischer, Piet A van den Brandt

\section{Summary}

Background Long-term exposure to particulate matter air pollution has been associated with increased cardiopulmonary mortality in the USA. We aimed to assess the relation between traffic-related air pollution and mortality in participants of the Netherlands Cohort study on Diet and Cancer (NLCS), an ongoing study.

Methods We investigated a random sample of 5000 people from the full cohort of the NLCS study (age 55-69 years) from 1986 to 1994. Long-term exposure to traffic-related air pollutants (black smoke and nitrogen dioxide) was estimated for the 1986 home address. Exposure was characterised with the measured regional and urban background concentration and an indicator variable for living near major roads. The association between exposure to air pollution and (cause specific) mortality was assessed with Cox's proportional hazards models, with adjustment for potential confounders.

Findings $489(11 \%)$ of 4492 people with data died during the follow-up period. Cardiopulmonary mortality was associated with living near a major road (relative risk 1.95, 95\% Cl 1.09-3.52) and, less consistently, with the estimated ambient background concentration (1.34, 0.68-2.64). The relative risk for living near a major road was 1.41 (0.94-2.12) for total deaths. Non-cardiopulmonary, non-lung cancer deaths were unrelated to air pollution (1.03, 0.54-1.96 for living near a major road).

Interpretation Long-term exposure to traffic-related air pollution may shorten life expectancy.

Lancet 2002; 360: 1203-09. Published online Sept 24, 2002 http://image.thelancet.com/extras/01art7366web.pdf See Commentary page 1184
Institute for Risk Assessment Sciences, Environmental and Occupational Health group, Utrecht University, Utrecht, Netherlands (G Hoek PhD, B Brunekreef PhD); Department of Nutritional Epidemiology, Netherlands Organisation for Applied Scientific Research, Nutrition and Food Research, Zeist (S Goldbohm PhD); Laboratory of Exposure Assessment and Environmental Epidemiology, National Institute of Public Health and the Environment, Bilthoven (P Fischer MSc); and Department of Epidemiology, Maastricht University, Maastricht, Netherlands (P A van den Brandt PhD)

Correspondence to: Dr Gerard Hoek, Institute for Risk Assessment Sciences, PO Box 80176, 3508 TD, Utrecht, Netherlands (e-mail: g.hoek@iras.uu.nl)

\section{Introduction}

Results of three prospective cohort studies ${ }^{1-3}$ have suggested that long-term exposure to particulate matter air pollution is associated with increased mortality from respiratory and cardiovascular disease and from lung cancer. However, because these studies were done in the USA, their findings might not apply to Europe, which possibly has different air pollution mixtures. Increased mortality was identified at particle concentrations that were lower than the yearly average National Ambient Air Quality Standard in the USA $\left(40 \mu \mathrm{g} / \mathrm{m}^{3}\right)$. In many European regions, including the Netherlands, the concentration of particles is presently at or above the highest concentrations recorded in the US cohort studies. ${ }^{4}$ The mortality associations are consistent with evidence that long-term exposure to air pollution causes chronic respiratory disease. ${ }^{5}$

Investigators of the cohort studies have compared several large, usually metropolitan, study regions with different ambient air pollution concentrations, on the assumption that exposure is uniform within each region. Such an assumption might have resulted in errors in estimation of exposure, especially for pollutants with important local sources. Confounding factors that vary between cities might also have distorted the relation with air pollution. The danger of such confounding is less if differences in exposure to air pollution between individuals within cities can be taken into account. In a study in four European countries, ${ }^{6}$ the concentration of nitrogen dioxide - an important trafficrelated pollutant-varied between small regions within cities. Results of this study ${ }^{7}$ suggested that traffic intensity and distance to major streets are important predictors of differences in long-term nitrogen dioxide concentrations within a city. Results of several studies ${ }^{8-10}$ have shown that chronic respiratory disease in children is associated with differences in the amount of air pollution within cities, and especially with distance to or living in busy streets.

Because initiation of new cohort studies of the relation between air pollution and mortality is expensive, and many years would pass before a conclusion can be reached, we have used data from an ongoing cohort study-the Netherlands Cohort study on Diet and Cancer (NLCS). ${ }^{11}$ In this study, the cohort is spread out over the Netherlands and thus captures variation in long-term exposure to air pollution within the country. Measurements at background sites of the National Air Quality Monitoring Network have shown that the differences in particle concentrations in the Netherlands is small (30-40\%). ${ }^{12}$ The long-term average concentration of ozone and secondary aerosol components (sulphate and nitrate) also does not differ by much. ${ }^{13}$ We therefore focused on traffic-related air pollutants, which are expected to show stronger spatial variation than ozone and aerosol components, and have been shown to be related to chronic morbidity.

\section{Methods}

Participants

The Netherlands Cohort study on Diet and Cancer (NLCS) ${ }^{11}$ is a prospective cohort study that was started in 1986, with 120852 participants aged 55-69 years at enrolment (58 279 or $48 \%$ men). Participants were 
recruited from the 204 (29\%) of 714 municipalities that had computerised population registries and were covered by cancer registries in 1986 (figure 1). All participants completed a self-administered questionnaire on diet and other risk factors in September, 1986.

The exact address of all study participants in 1986 is known. A residential history is available that allows identification of up to four previous towns of residence. The NLCS is a case-cohort study from which a random sample of 5000 participants were followed up every 2 years for migration and vital status by contacting the participants and the municipalities. This information was used to estimate the person-time experience of the cohort. For our sample, we assessed the $4492(90 \%)$ of 5000 participants whose questionnaire data were complete. The NLCS study was approved by the medical ethical committees from Maastricht University and TNO.

\section{Procedures}

Motorised traffic emissions result in small-scale spatial variations (high concentrations at short distances from major roads) and affect urban and regional background air pollution concentrations. We quantified small-scale spatial variations in air pollution concentrations by calculating proximity to major roads. For urban and regional background concentration, we used concentration data for the pollutants black smoke and nitrogen dioxide, both of which are indicators of traffic-related air pollution. Exposure to traffic-related air pollution has been characterised by estimating long-term average ambient air pollution concentrations at the 1986 home address. Details of the exposure assessment procedures have been described previously. ${ }^{14}$ Briefly, the addresses were geocoded with a geographic information system. Long-term average exposure to outdoor air pollution was calculated as a function of the regional background pollution, pollution from urban sources (urban background), and pollution from local sources (nearby streets).

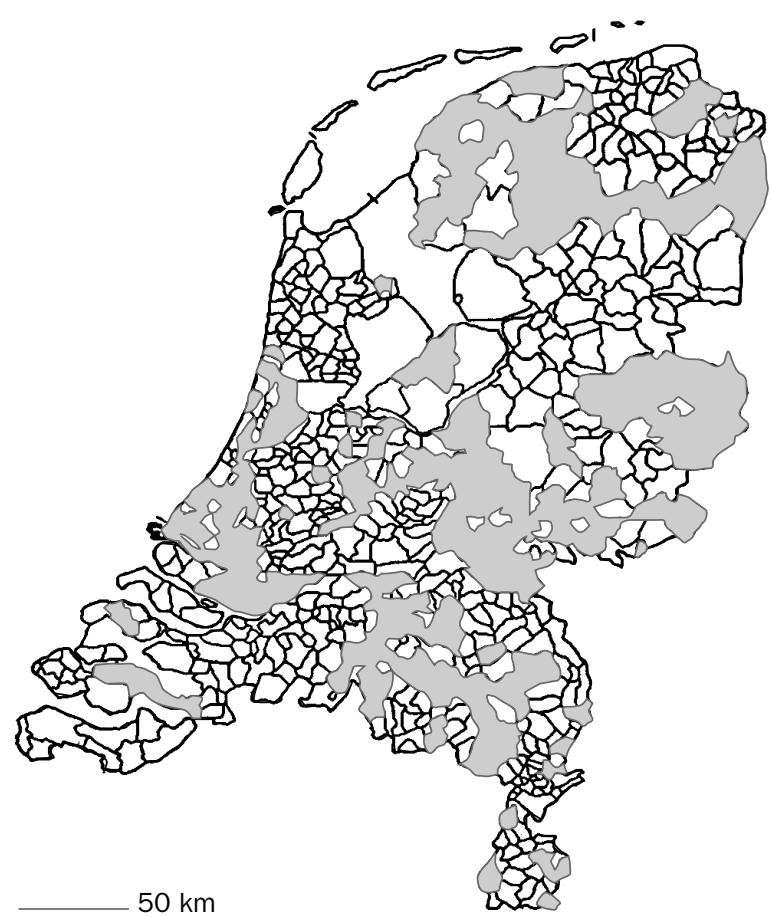

Figure 1: Distribution of the municipalities of the NLCS study population over the Netherlands

Area of the Netherlands is $41562 \mathrm{~km}^{2}$. Shaded regions are included communities.
The regional background concentration was estimated by inverse distance squared weighted interpolation of black smoke and nitrogen dioxide concentrations measured at all regional background stations of the National Air Quality Monitoring Network. We used the average concentration between 1987 and 1990 - the first 4 years of follow-up of the cohort study. Data for the preceding period were not used because data for black smoke were not available for a sufficient number of sites before 1987. Investigators of the initial American cohort studies ${ }^{1,2}$ used a similar time period.

We estimated the additional urban background component from a regression model with measured concentrations of black smoke and nitrogen dioxide from the National Air Quality Monitoring Network as the dependent variable (1987-90 average), and address density of the four position postal code of the National Air Quality Monitoring Network sites as the independent variable. Address density is a measure of amount of urbanisation; the four-position postal code covers an area of about 10000 inhabitants (neighbourhood scale). To estimate the additional urban background, we multiplied the regression slopes from the black smoke and nitrogen dioxide models with the address density of the four position postal code of the home address of every study participant. The sum of the regional and additional urban background is referred to as the (urban) background exposure.

Distances of the home address to major roads were calculated through a geographic information system. Participants living within $100 \mathrm{~m}$ of a freeway or within $50 \mathrm{~m}$ of a major urban road were judged exposed. We estimated air pollution associated with living near a major road using measurement data from two Dutch traffic studies. ${ }^{15,16}$ On the basis of these data, living within $100 \mathrm{~m}$ of a freeway resulted in exposure to a black smoke concentration of $4.4 \mu \mathrm{g} / \mathrm{m}^{3}$ and a nitrogen dioxide concentration of $11 \mu \mathrm{g} / \mathrm{m}^{3}$. People living within $50 \mathrm{~m}$ of a major inner-city road were estimated to be exposed to $13 \mu \mathrm{g} / \mathrm{m}^{3}$ black smoke and $8 \mu \mathrm{g} / \mathrm{m}^{3}$ nitrogen dioxide. These estimates were assigned to each exposed address, independent of the actual distance to the road.

Cross-validation showed that prediction errors for interpolation of the regional background were about $15 \%$ of the range in regional background concentration. Prediction errors for estimating the urban background were about $25 \%$ of the range in background concentrations.

Mortality was assessed in the subcohort between Sept 17, 1986 (start of the study), and Oct 1, 1994, a period of about 8 years, with no loss to follow-up. Data for mortality were obtained from the Dutch Central Bureau of Genealogy. Data for cause of death were subsequently processed at the Dutch Central Bureau of Statistics. Causes of death included cardiovascular, respiratory, cardiopulmonary, lung cancer, and non-cardiopulmonary, non-lung cancer.

\section{Data analysis}

We analysed data with Cox's proportional hazards model, with adjustment for potential confounders. For participants who died, time in study was calculated as the difference between start of follow-up and date of death; for those who were alive at the end of follow-up, time in study was the difference between start and end of follow-up. For these individuals, time of study was judged censored. In the analysis of death by cause, time in study for participants who died from causes other than those analysed, were judged censored.

We used two models of exposure for every pollutant. First, the background concentration was entered in the model with the indicator variable for living near a major road. Second, we entered the sum of the background and 
the estimated contribution from living near a major road to air pollution concentrations.

Confounder variables were selected a priori as the confounders considered in the initial American cohort studies $^{1,2}$ and previous analyses of the NLCS cohort on the relation between (lung) cancer and diet. In addition to the variables available in the American cohort studies, we also assessed the effect of adjustment for diet. Age was entered as a continuous variable because an exploratory analysis showed that mortality was predicted more accurately if the variable was continuous than if we used two indicator variables for 5-year age categories. We accounted for active smoking by including the following variables: indicator variables for current and ex-smokers of cigarettes (never smokers were baseline); number of cigarettes smoked for ex-smokers and current smokers separately; number of years smoking cigarettes for ex-smokers and current smokers separately. ${ }^{2}$ Smoking of cigars and pipes was unrelated to mortality after adjustment for cigarette smoking. Passive smoking was judged by the question on whether the partner smoked. The education of the participant was coded into three categories: primary school, lower vocational education, and high school and higher. We coded the last occupation of the participant into six categories: not codable, never paid work, blue collar, lower white collar, upper white collar, other. The question of occupational exposure to dusts, fumes, and gases (used in the US cohort studies) was not available. However, because multiple occupational factors might have been related to allcause mortality (physical activity, stress, noise) a broader classification could be preferable. We used indicator variables for Quetelet index (bodyweight divided by height squared; categories $<22.5,22.5-24.5,24.5-26.5,>26.5$ $\left.\mathrm{kg} / \mathrm{m}^{2}\right)$ and alcohol intake $(0,0-5,5-15,15-30,>30 \mathrm{~g} /$ day $)$, because of evidence of non-monotone relations with mortality. We used continuous variables for total fat intake and for vegetable and fruit consumption. Finally, we adjusted for regional indicators of poverty (income distribution, proportion of the population aged 15-64 years on social security). These data were available for the fourposition postal code area (neighbourhood scale) from the Central Bureau of Statistics. All epidemiological data analyses were done with SPSS 7.5.2 and SPSS 8.0 (causespecific analyses). Geographic information system calculations were done with Arcinfo.

\section{Role of the funding source}

The sponsor of the study had no role in study design, data collection, data analysis, data interpretation, or in the writing of the report.

\section{Results}

Table 1 shows participants' baseline characteristics. 489 participants died during the study - most from natural causes (table 2). We identified geographical coordinates for the addresses of 4466 (99\%) of 4492 participants. 206 (5\%) participants lived close to a major road: $132(3 \%)$ within $100 \mathrm{~m}$ of a freeway, and $77(2 \%)$ within $50 \mathrm{~m}$ of a major urban road.

The estimated long-term ambient concentration of black smoke and nitrogen dioxide at the 1986 home address varied greatly between participants (figure 2, table 3 ). As a proportion of the median, the difference in concentration of background and local black smoke between the 5th and 95th percentile was $59 \%$, with $83 \%$ for nitrogen dioxide. The local contribution was correlated with the estimated background concentration for black smoke $(p<0 \cdot 0001)$ and for nitrogen dioxide $(p<0.0001)$. The correlation between black smoke and nitrogen dioxide was 0.92 for the

\begin{tabular}{|c|c|c|}
\hline & Alive $(n=4003)$ & Dead $(n=489)$ \\
\hline \multicolumn{3}{|l|}{ Characteristic } \\
\hline Men & 1859 (46\%) & 315 (64\%) \\
\hline Age (years) & $61(58-65)$ & $63(59-66)$ \\
\hline Current cigarette smokers & $1089(27 \%)$ & $197(40 \%)$ \\
\hline Cigarettes smoked daily & $15(9-20)$ & $15(12-20)$ \\
\hline Years smoked & $40(35-45)$ & $42(38-47)$ \\
\hline Former cigarette smokers & $1395(35 \%)$ & $183(37 \%)$ \\
\hline Cigarettes smoked daily & $14(6-20)$ & $18(10-20)$ \\
\hline Years smoked & $26(18-35)$ & $31(22-40)$ \\
\hline $\begin{array}{l}\text { Less than secondary school } \\
\text { education }\end{array}$ & $1220(31 \%)$ & $176(37 \%)$ \\
\hline Blue collar job & $1179(31 \%)$ & 167 (36\%) \\
\hline $\begin{array}{l}\text { Neighbourhood socioeconomic } \\
\text { score* }\end{array}$ & $41(36-46)$ & $42(37-47)$ \\
\hline Quetelet index $\left(\mathrm{kg} / \mathrm{m}^{2}\right)$ & $24 \cdot 8(23 \cdot 1-26 \cdot 8)$ & $24 \cdot 7(22 \cdot 8-27 \cdot 0)$ \\
\hline Alcohol consumption (g/day) & $4 \cdot 1(0 \cdot 3-15 \cdot 0)$ & $5 \cdot 1(0 \cdot 0-16 \cdot 8)$ \\
\hline Total fat intake (g/day) & $81(64-99)$ & $82(66-99)$ \\
\hline Vegetable consumption (g/day) & $181(139-234)$ & $178(129-229)$ \\
\hline Fruit consumption (g/day) & $157(96-237)$ & $139(83-219)$ \\
\hline
\end{tabular}

Values are number (\%) or median (IQR). *Proportion of the population of the four position postal code area with a yearly income of less than Dfl19 000.

Table 1: Characteristics of the NLCS subcohort $(n=4492)$ by death status at end of follow-up

estimated background concentration and 0.85 for the concentration estimate including the local scale.

The question about previous towns of residence was adequately completed by 3946 participants (88\%). 3539 $(90 \%)$ of these participants had lived for 10 years or longer in their 1986 town. Mean duration of residence was 35 years (SD 19.83).

Before adjustment for confounders, exposure to black smoke and nitrogen dioxide was associated with all-cause mortality (table 4). After adjustment for confounders, the association between background exposures and mortality became smaller and non-significant, whereas the association between living near a major road and all-cause mortality increased slightly. Addition of diet and alcohol to the confounder model did not change the association with any air pollution exposure (data not shown). For participants who had lived for 10 years or longer in their 1986 town, lower effect estimates were found for the background exposures than in all participants, whereas the association between living near a major road and mortality became stronger and significant (table 4). When the adjusted analyses were restricted to the $2509(72 \%)$ participants who used to smoke or had never smoked, the estimate for living near a major road remained unchanged (relative risk $1 \cdot 49$, $95 \%$ CI 0.91-2.43), whereas the estimate for the background exposure to black smoke was strongly reduced $(1 \cdot 02,0.59-1 \cdot 73)$. When only the background exposure was included in the model (as in the US cohorts), slightly increased rate ratios were found for black smoke $(1 \cdot 19$, $0 \cdot 78-1 \cdot 82)$, and nitrogen dioxide $(1 \cdot 27,0.85-1 \cdot 89)$. The small change compared with the estimates in table 4 is consistent with the low correlation between background and local scale exposure.

The validity of the proportional hazards assumption was

\begin{tabular}{|c|c|c|}
\hline$\overline{\text { Cause }}$ & ICD-9 codes & Deaths \\
\hline All cause & All & 489 (11\%) \\
\hline Natural cause & $<800$ & 482 (11\%) \\
\hline Cardiovascular & $400-440$ & $158(4 \%)$ \\
\hline Respiratory & $460-519$ & 27 (1\%) \\
\hline Cardiopulmonary & $400-440$ or $460-519$ & $185(4 \%)$ \\
\hline Lung cancer & 162 & $60(1 \%)$ \\
\hline $\begin{array}{l}\text { Non-cardiopulmonary, } \\
\text { non-lung cancer }\end{array}$ & $\begin{array}{l}\text { Not } 400-440 \text {, not } 162 \text {, and } \\
\text { not } 460-519\end{array}$ & $244(5 \%)$ \\
\hline
\end{tabular}

Table 2: Number of deaths during follow-up, 1986-94, NLCS

subcohort $(n=4492)$ 

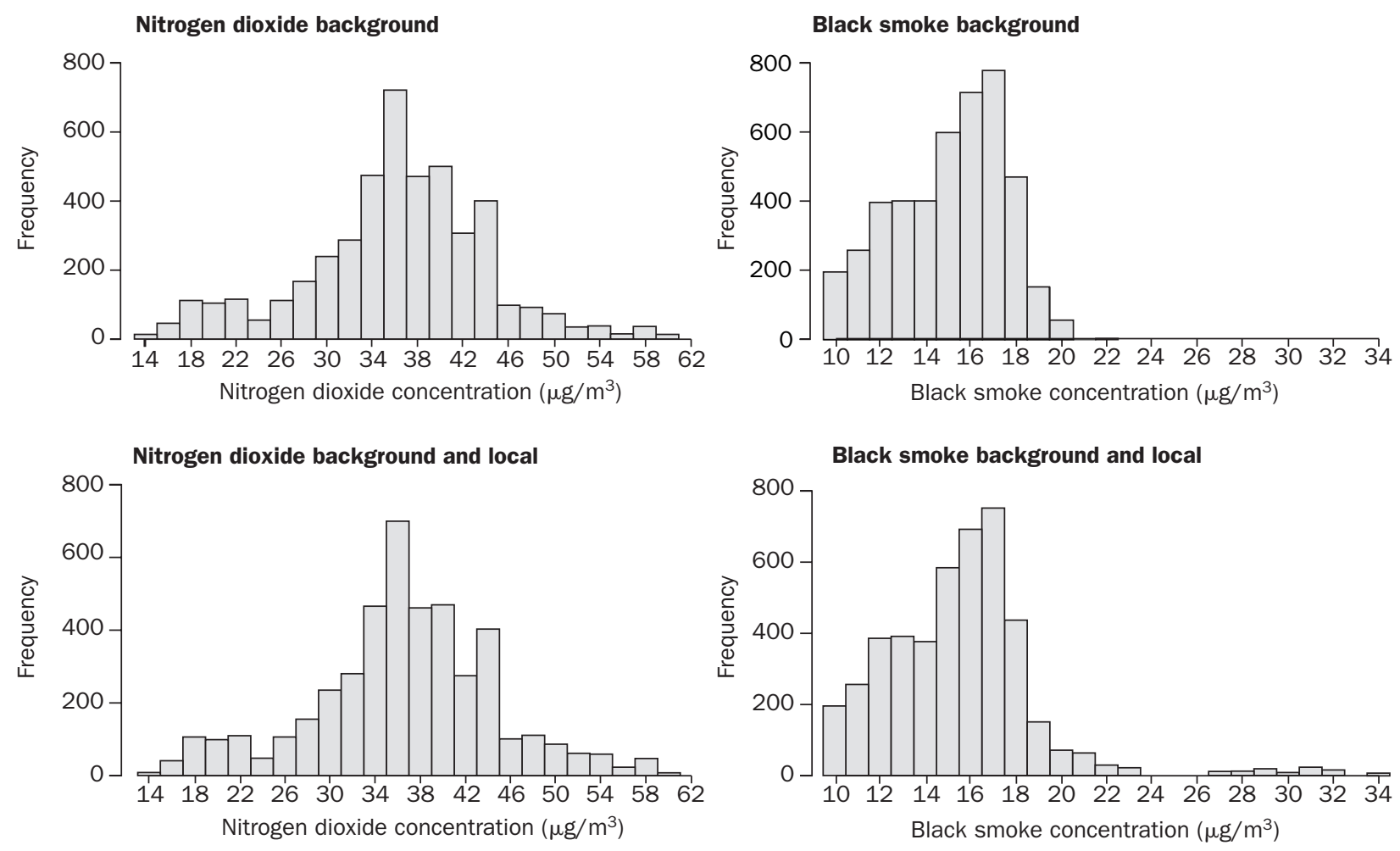

Figure 2: Distribution of long-term average black smoke and nitrogen dioxide exposures at the 1986 home address

tested by preparing curves of the $\log$ ( $-\log$ of survival function) versus time on study for those living near a major road and those not. The plots were parallel, suggesting that the Cox's proportional hazards model was reasonable for these data.

In a reanalysis of the two first US cohort studies, education modified the effect of pollution on mortality, with higher air pollution effect estimates in those without high school education. ${ }^{17}$ We assessed effect-modification by education by including interaction terms between education and black smoke exposure including the local scale (we did not have enough power to look at interactions with the indicator variable for living near a major road separately). The adjusted rate ratios for black smoke were 1.62 $(0 \cdot 97-2 \cdot 70)$ for participants with only primary school education; $1.24(0 \cdot 79-1.94)$ for those with lower vocational education; and $1 \cdot 16(0 \cdot 64-2 \cdot 10)$ for those with high school and higher education. The differences between these effect estimates were not significant $(p=0.434$ for medium-low and $\mathrm{p}=0.403$ for high-low), which suggests that we did not have sufficient power to assess effect modification, but these values were almost the same as the findings in the two American cohort studies.

All relative risk estimates for cardiopulmonary mortality were substantially larger than the corresponding risk estimates for all-cause mortality (table 4). Addition of dietary and alcohol variables to the confounder model did not change the association with any exposure to air pollution. For participants who had lived 10 years or longer in their 1986 town, we recorded lower effect estimates for background exposures (black smoke relative risk 1.07, $0 \cdot 51-2 \cdot 25)$, whereas the association between living near a major road and mortality remained stable $(2 \cdot 18$, $1 \cdot 20-3 \cdot 94)$.

We identified no association between any of the exposures and non-cardiopulmonary, non-lung cancer mortality (table 4). In the different confounder models, the relative risk estimates for living near a major road ranged from $0.95(0.48-1 \cdot 87)$ to $1.06(0.54-2 \cdot 09)$, neither of which were significant.

Too few people died from respiratory disorders and lung cancer to obtain stable estimates for the indicator variable for living near a major road. The adjusted relative risk estimates for lung cancer deaths for the exposure estimates including the local scale were $1.06(0.43-2.63)$ for black smoke and $1.25(0.42-3 \cdot 72)$ for nitrogen dioxide. No stable estimates were obtained for respiratory deaths.

The air pollution effect estimates were substantially smaller than those associated with active smoking. The rate ratio for all-cause mortality of a current smoker who had smoked 20 cigarettes a day for 25 years (numbers used in one of the US cohort studies ${ }^{2}$ ) was 2.38 (1.58-3.57) compared with a never-smoker (relative risk 1.41 [0.94-2.11] for living near a major road). The rate ratio for

\begin{tabular}{|c|c|c|c|c|c|c|c|c|}
\hline & Minimum & P5 & P25 & Median (IQR) & Mean (SD) & P75 & P95 & Maximum \\
\hline \multicolumn{9}{|l|}{ Black smoke } \\
\hline Background & $9 \cdot 6$ & $10 \cdot 6$ & $13 \cdot 2$ & $15 \cdot 5$ & $15 \cdot 1(2 \cdot 5)$ & $17 \cdot 0$ & $18 \cdot 6$ & $21 \cdot 6$ \\
\hline Background and local & $9 \cdot 6$ & $10 \cdot 6$ & $13 \cdot 2$ & $15 \cdot 6$ & $15 \cdot 5(3 \cdot 2)$ & $17 \cdot 1$ & $19 \cdot 9$ & $35 \cdot 8$ \\
\hline \multicolumn{9}{|l|}{ Nitrogen dioxide } \\
\hline Background & $14 \cdot 7$ & $20 \cdot 3$ & $32 \cdot 4$ & $36 \cdot 4$ & $36 \cdot 1(7 \cdot 9)$ & $40 \cdot 8$ & $48 \cdot 2$ & $59 \cdot 5$ \\
\hline Background and local & $14 \cdot 7$ & $20 \cdot 3$ & $32 \cdot 6$ & $36 \cdot 6$ & $36.6(8 \cdot 3)$ & 41.5 & $50 \cdot 7$ & $67 \cdot 2$ \\
\hline
\end{tabular}

*Background is based on regional and urbanisation scale; local adds a quantitative estimate of living near a major road to the background for those people living close to a major road. $\mathrm{P} 5=5$ th percentile.

Table 3: Description of estimated air pollution exposures $\left(\mu \mathrm{g} / \mathrm{m}^{3}\right)$ in the NLCS subcohort $(n=4466)$ 


\begin{tabular}{|c|c|c|c|c|c|c|}
\hline \multirow[t]{2}{*}{ Model* } & \multirow[t]{2}{*}{ Variable } & \multirow[t]{2}{*}{ Cardiopulmonary } & \multirow{2}{*}{$\begin{array}{l}\text { Non-cardiopulmonary, } \\
\text { non-lung cancer }\end{array}$} & \multicolumn{3}{|l|}{ All-cause } \\
\hline & & & & Unadjusted $(n=4466)$ & Adjusted $\dagger(n=3464)$ & Adjusted $\ddagger(n=2788)$ \\
\hline \multirow[t]{2}{*}{1} & Black smoke (background) & $1.34(0.68-2 \cdot 64)$ & $1 \cdot 15(0 \cdot 63-2 \cdot 10)$ & $1.37(0.95-1.97)$ & $1 \cdot 17(0 \cdot 76-1 \cdot 78)$ & $1.04(0.65-1.64)$ \\
\hline & Major road & $1.95(1.09-3.51)$ & $1.03(0.54-1.96)$ & $1.35(0.93-1.95)$ & $1.41(0.94-2 \cdot 12)$ & $1.53(1.01-2.33)$ \\
\hline 2 & Black smoke (background and local) & $1 \cdot 71(1 \cdot 10-2 \cdot 67)$ & $1.09(0.71-1.69)$ & $1.37(1.06-1.77)$ & $1.32(0.98-1.78)$ & $1.31(0.95-1.80)$ \\
\hline \multirow[t]{2}{*}{3} & Nitrogen dioxide (background) & $1.54(0.81-2.92)$ & $1.07(0.61-1.90)$ & $1.37(0.97-1.94)$ & $1 \cdot 24(0 \cdot 83-1 \cdot 86)$ & $1.09(0.70-1.69)$ \\
\hline & Major road & $1.94(1.08-3.48)$ & $1.04(0.54-1.97)$ & $1.34(0.93-1.95)$ & $1.41(0.94-2 \cdot 11)$ & $1.53(1.01-2.32)$ \\
\hline 4 & Nitrogen dioxide (background and local) & $1.81(0.98-3.34)$ & $1.08(0.63-1.85)$ & $1.45(1.05-2 \cdot 01)$ & $1.36(0.93-1.98)$ & $1.25(0.83-1.89)$ \\
\hline
\end{tabular}

Values are relative risk $(95 \% \mathrm{Cl})$. Values are calculated for concentration changes from the 5 th to the 95 th percentile. For black smoke, this was rounded to $10 \mu \mathrm{g} / \mathrm{m}^{3}$, for $\mathrm{NO}_{2} 30 \mu \mathrm{g} / \mathrm{m}^{3}$. Adjusted for age, sex, education, Quetelet-index, occupation, active and passive cigarette smoking, and neighbourhood socioeconomic score.

* Models 1 and 3 contain the background concentration and an indicator variable for living near a major road. Models 2 and 4 contain an estimate of the home address concentration, by adding to this background concentration a quantitative estimate of living near a major road. Major road is an indicator variable $(0 / 1,1$ indicating living near a major road). †Adjusted for confounders. $\ddagger$ For individuals living 10 years or longer at their 1986 address, adjusted for above confounders.

Table 4: Risk of cardiopulmonary, non-cardiopulmonary non-lung cancer, and all-cause mortality associated with long-term exposure to traffic related air pollution, NLCS subcohort 1986-94

cardiopulmonary mortality of a current smoker who had smoked 20 cigarettes a day for 25 years was $3 \cdot 37$ $(1 \cdot 84-6 \cdot 17)$ compared with a never-smoker $(1 \cdot 94$ [1.08-3.48] for living near a major road).

\section{Discussion}

We assessed the association between long-term exposure to traffic-related air pollution and cause-specific mortality in a cohort of elderly people and identified a consistent association between cardiopulmonary mortality and living near a major road. The association between mortality and the estimated ambient background concentration of the indicator pollutants black smoke and nitrogen dioxide was less consistent.

Our results are much the same as those in two US cohort studies. ${ }^{1,2}$ In the US cohort studies and in our study, air pollution was associated with all-cause mortality, with stronger associations for cardiopulmonary deaths and no association for other causes of death. Quantitatively, the effect estimates are difficult to compare because we assessed different pollutants and assigned individual estimates of ambient air pollution, whereas the US studies assigned the same estimate to all participants living in the same community. In the Six City study, ${ }^{1}$ the relative risks for comparison of the most with the least polluted city were $1 \cdot 26,1 \cdot 37,1 \cdot 37$, and 1.01 for all-cause, cardiopulmonary, lung cancer, and other deaths, respectively. The average concentrations ranged from 11 to $30 \mu \mathrm{g} / \mathrm{m}^{3}$ for particulate matter 2.5. In the American Cancer Society study, ${ }^{2}$ the relative risk for comparison of the most with the least polluted city was $1 \cdot 15,1 \cdot 26,1 \cdot 36$, and 1.01 for all-cause, cardiopulmonary, lung cancer, and other deaths, respectively, with average concentrations ranging from $9 \mu \mathrm{g} / \mathrm{m}^{3}$ to $33.5 \mu \mathrm{g} / \mathrm{m}^{3}$ for particulate matter 2.5 . Investigators from a study of non-smoking California Seventh-day Adventists ${ }^{3}$ recorded similar relative risk estimates for all-cause and cardiopulmonary deaths, with the highest relative risks for lung cancer deaths. Although investigators in the US cohort studies and a study in Stockholm ${ }^{18}$ identified an association with lung cancer deaths, we recorded no such association. However, the number of cases was small in our study, leading to wide CIs.

One difference with the US cohort studies is that we assessed exposure to air pollution on a smaller spatial scale. In the first two studies, ${ }^{1,2}$ the same exposure was assigned to all participants living within the same city or metropolitan area. In the AHSMOG study, ${ }^{3}$ interpolation of concentrations from network sites at the zip code centroid of the residential address was used. Therefore, differences within metropolitan regions were taken into account only if the network was sufficiently dense. None of the three studies took proximity to major roads into account. The association in our study between living near a major road and mortality was stronger than the association between mortality and the estimated urban or rural background concentrations of traffic-related air pollution: the relative risk estimates for living near a major road were not sensitive to inclusion of different sets of confounders, restriction to participants who had lived for 10 years or longer at their 1986 home address, and restriction to never-smokers and ex-smokers. By contrast, relative risk estimates for estimated background concentrations varied substantially across these models. Although the associations for background exposure were less significant and less consistent in different models, we do not interpret our study as showing no relation between background exposure and mortality. The magnitude of the effect estimates for cardiopulmonary mortality was certainly not trivial, and they were not randomly distributed around unity. Exclusion of the indicator variable living near a major road from the model did not substantially affect the effect estimate for background concentrations.

Biases could result from differential selection, insufficient control for confounding, and exposure misclassification. The study population for the original NLCS cohort originated from 204 municipalities throughout the country. Although the response rate to the baseline questionnaire was rather low (36\%), data for demographic variables, and smoking and dietary habits suggested that the response had not adversely affected determinant distributions in the cohort. ${ }^{11}$ In prospective cohort studies, incomplete followup is usually the most important source of selection bias. Since the person year and mortality follow-up was nearly $100 \%$ complete, selection bias is unlikely to be important in our study.

We cannot exclude that (unmeasured) confounders are to some extent responsible for the associations. We did adjust for all confounders accounted for in the US cohort studies, with the exception of ethnic origin. Race is not an issue in the NLCS because the samples from the municipalities included only white participants. We also adjusted for major dietary variables and a regional indicator of poverty. A limitation in our and the US studies is that confounder data were available only at baseline. Living near a major road might also include factors other than air pollution. However, living near a major road was not associated with most of the confounders we adjusted for (including age, sex, number of smokers, number of years smoked, regional poverty, diet). The only significant $(\mathrm{p}<0 \cdot 10)$ differences between those living near a major road and those not living near a major road were for body-mass index, education, occupation, and number of cigarettes smoked by current smokers. Those living near a major road had in fact slightly higher education, worked less frequently in blue-collar jobs, and smoked fewer cigarettes. So, since the true association would become stronger if residual confounding were 
present, residual confounding by these factors is very unlikely to account for the association between living near a major road and mortality. Consistently, the unadjusted effects estimates for living near a major road were much the same as the effect estimates after adjustment for confounders (they actually increased slightly). Average body-mass index was lower in those living near a major road than those who did not, mostly because a larger proportion had low body-mass index $\left(<22.5 \mathrm{~kg} / \mathrm{m}^{2}\right)$. The proportion of participants with a high body-mass index $\left(>26.5 \mathrm{~kg} / \mathrm{m}^{2}\right)$ did not differ between these two groups.

As in the reanalysis of the US cohort studies, ${ }^{17}$ we included regional indicators of poverty as potential confounders. Investigators in the US studies used the metropolitan scale to characterise contextual variables. We believe that for contextual variables, the neighbourhood scale is appropriate and the four-position postal code in the Netherlands is a good approximation of the neighbourhood scale.

Traffic noise associated with living near a major road could also affect cardiovascular health. However, in a large study ${ }^{19}$ on the relation between measured traffic noise exposure and cardiovascular disease, the association was not consistent.

We did not apply the new spatial analytical models developed in the framework of the Health Effects Institute Particle Epidemiology Reanalysis project. ${ }^{17,20}$ These models account for spatial autocorrelation of air pollution, covariates, and mortality, and possibly led to underestimation of the standard errors, but the effect estimates are unbiased. ${ }^{17,20}$ In the reanalysis of the American Cancer Society study, ${ }^{17,20}$ control for spatial autocorrelation indeed did not change the effect estimates substantially, but CIs became slightly wider. We expect that our results are less sensitive to spatial autocorrelation, since we estimated exposure on a smaller spatial scale (differentiating exposures within cities).

Motorised traffic emissions result in small-scale spatial variations (high concentrations at short distances from major roads), which we have accounted for with the indicator variable of living near a major road. In addition, traffic emissions affect the (urban and regional) background air pollution concentrations, which we accounted for by using measured concentrations of black smoke and nitrogen dioxide. Black smoke and nitrogen dioxide are thus used as indicators of traffic related air pollution, but not necessarily the components causally related to mortality. Black smoke is measured by light absorbance of filters used to gather particulate matter from the air. Today, the concentration of black smoke mostly arises from elemental carbon emissions from diesel engines, whereas nitrogen dioxide result from emissions from all motorised vehicles. The major source contributing to black smoke concentrations is Dutch road traffic: $65 \%$ in urban environments. ${ }^{21}$ About $50 \%$ of the national nitrogen dioxide emissions are due to motorised traffic. Because of the low emission height of traffic-related air pollutants, and the concentration of traffic in urban environments, the contribution to ambient nitrogen dioxide concentrations to which human beings are actually exposed is much higher than $50 \%$.

We assessed exposure to traffic-related air pollution with objective methods. Therefore bias due to self reported exposures $^{8}$ was not an issue. The method to assess local scale exposures is a simplification, since the actual exposure near a major road may depend on the exact distance to the road, traffic intensity, and configuration of the street. Data for these factors were not available for many roads, however. Another limitation of our study is that we used exposure data for 1987-90 (ie, the first 4 years of the 8-year follow-up) since black smoke data for earlier time periods were not available. Investigators of the American cohort studies $^{1,2}$ used a similar time period. Although air pollution concentrations show trends over time due to emission abatement measures or changes in economic activity, substantial changes are usually slow (taking place over decades rather than years) and typically affect large regions in the same way. Serious misclassification of exposure would therefore be unlikely because we estimated this value for the first 4 years of the 8-year follow-up.

We have assessed exposure to motorised traffic emissions by estimating the outdoor concentration at the home address, an approximation of the true exposure of participants. In developed countries, people generally spend a large proportion of their time in their own homes. Therefore, a large part of the exposure to pollutants of outdoor origin probably occurs indoors. There is growing evidence that for a number of important pollutants including fine particles, indoor air in homes is substantially affected by outdoor air. ${ }^{22}$ Investigators of a study ${ }^{15}$ in Amsterdam recorded differences in concentration between major and small side streets in both outdoor and indoor air. The black smoke concentration ratio between major and small streets was 1.84 for outdoor air and 1.83 for indoor air. Such ratios are consistent with the near quantitative penetration of fine particles in indoor air. ${ }^{22}$ Results of a validation study ${ }^{23}$ showed that both outdoor and personal nitrogen dioxide exposure of children was significantly affected by address density of the city district and by traffic density and distance to a nearby highway.

We recorded associations with cardiopulmonary mortality, but not with other causes of death. In time series studies $^{5}$ of short-term effects of air pollution on mortality, effects are largest for respiratory and cardiovascular causes of death. Kuenzli and colleagues ${ }^{24}$ provided a model for linking cohort studies, time series studies, and chronic effects. Cohort studies measure effects related to short-term and long-term exposures and therefore provide a more comprehensive estimate of the effects of air pollution. The results are also consistent with those of studies ${ }^{8-10,25,26}$ showing associations between living near major roads and chronic disease. The specificity of the association and the consistency with chronic morbidity studies, adds to the plausibility of traffic-related air pollution effects.

Because the effect estimates in the US cohort studies imply a loss life expectancy of 1-2 years-a substantial public health problem - further studies are needed of such associations. ${ }^{27}$ The effect estimates for living near a major road in our study tended to be even larger. In a recent health impact assessment ${ }^{28}$ from Switzerland, France, and Austria, estimates of the number of deaths due to air pollution were based on the first two US cohort studies. ${ }^{1,2}$ It is therefore crucial that data from more cohort studies become available.

The association we recorded between living near a major road and mortality was stronger than those for the urban or rural background concentration. The composition of the air pollution mixture might differ between the local and the background scale so that nitrogen dioxide and black smoke are differentially associated with other, unmeasured components at the different geographical scales. The local scale is mostly characterised by fresh emissions, including large numbers of ultrafine particles. The background scale is characterised by more aged emissions, including aerosol nitrates. Insufficient data exist for the toxic effects of particles gathered in different locations to allow further interpretation. Traffic emissions contain many pollutants that might be responsible for the mortality association, including ultrafine particles, diesel soot, and nitrogen 
oxides. ${ }^{29}$ Because of the much higher concentrations of nitrogen dioxide associated with gas cooking than those recorded from traffic emissions, this pollutant probably does not cause death. Furthermore, results of experimental studies $^{30}$ have shown little response to high nitrogen dioxide concentrations in volunteers. The large number of ultrafine particles might be associated through pulmonary inflammation and release of mediators in the blood with increased plasma viscosity. ${ }^{31}$ Increased plasma viscosity could lead to cardiovascular events including death. ${ }^{31}$ Although increased plasma viscosity has been associated with air pollution, ${ }^{32}$ the link with ultrafine particles is not clear. Diesel soot also causes pulmonary inflammation, ${ }^{33}$ which might be associated with subsequent cardiovascular events. ${ }^{31}$

\section{Contributors}

G Hoek contributed to the study design, especially in exposure assessment: did the geographic information systems and air pollution data collection, exposure modelling, epidemiological data analysis; and wrote the report. B Brunekreef was the main investigator of the air pollution add-on part; secured the funding for the study; provided the basic study design; provided comments to the exposure modelling and epidemiological data analysis and the draft. P Fischer contributed to the design of the geographic information systems and air pollution data collection and exposure modelling and commented on the draft. S Goldbohm and P van den Brandt are the main investigators of the NLCS study; secured the funding of the original cohort study; contributed the mortality and confounder data; contributed to the epidemiological analysis of the data, and commented on the draft.

\section{Conflict of interest statement}

None declared.

\section{Acknowledgments}

We thank Sacha van de Crommert, Jolanda Nelissen,

Harry van Montfort, Conny de Zwart and Ruud Schmeitz (University Maastricht), and Willy van Dijk and Henny Brants (TNO) for their contribution to the data entry, data management, and follow-up of the cohort, and Carla van Wiechen (National Institute of Public Health and the Environment) for valuable advice on geographic information systems calculations. This study was supported exclusively by research grant 32.96.40 from the Netherlands Asthma Foundation.

\section{References}

1 Dockery DW, Pope CA III, Xu X, et al. An association between ai pollution and mortality in six US cities. N Engl f Med 1993; 329: 1753-59.

2 Pope CA III, Thun MJ, Namboodiri MM, et al. Particulate air pollution as a predictor of mortality in a prospective study of US adults. Am f Respir Crit Care Med 1995; 151: 669-74.

3 Abbey DE, Nishino N, McDonnell WF, et al. Long-term inhalable particles and other air pollutants related to mortality in nonsmokers. Am $\mathcal{F}$ Respir Crit Care Med 1999; 159: 373-82.

4 Hoek G, Forsberg B, Borowska M, et al. Wintertime PM10 and black smoke concentrations across Europe: results from the PEACE study. Atmos Environ 1997; 31: 3609-22.

5 Pope CA III, Dockery DW, Schwartz J. Review of epidemiological evidence of health effects of particulate air pollution. Inhal Toxicol 1995; 7: $1-18$

6 Lebret E, Briggs D, van Reeuwijk H, et al. Small area variations in ambient $\mathrm{NO}_{2}$ concentrations in four European areas. Atmos Environ 2000; 34: 177-85.

7 Briggs DJ, Collins S, Pryl K, Smallbone K, van der Veen A. Mapping urban air pollution using GIS: a regression-based approach. Int f Geograph Inform Sci 1997; 11: 699-718.

8 Weiland SK, Mundt KA, Rueckmann A, Keil U. Self-reported wheezin and allergic rhinitis in children and traffic density on street of residence. Ann Epidemiol 1994; 4: 243-47.

9 Wist M, Reitmeir P, Dold S, et al. Road traffic and adverse effects on respiratory health in children. BMF 1993; 307: 596-600.
10 Edwards J, Walters S, Griffith RK. Hospital admissions for asthma in preschool children: relationship to major roads in Birmingham, United Kingdom. Arch Environ Health 1994; 49: 223-27.

11 Van den Brandt PA, Goldbohm RA, van 't Veer P, Volovics A, Hermus RJJ, Sturmans F. A large-scale prospective cohort study on diet and cancer in the Netherlands. F Clin Epidemiol 1990; 43: 285-95.

12 van der Wal JT, Janssen LHJM. Analysis of spatial and temporal variations of PM10 concentrations in the Netherlands using Kalman filtering. Atmos Environ 2000; 34: 3675-87.

13 Hoek G, Mennen MG, Allen GA, Hofschreuder P, van der Meulen T. Concentrations of acidic air pollutants in the Netherlands. Atmos Environ 1996; 30: 3141-50.

14 Hoek G, Fischer P, van den Brandt P, Goldbohm S, Brunekreef B. Estimation of long-term average exposure to outdoor air pollution for a cohort study on mortality. F Expo Anal Environ Epidemiol 2001; 11: 459-69.

15 Fischer PH, Hoek G, Reeuwijk H, et al. Traffic-related differences in outdoor and indoor concentrations of particles and organic compounds in Amsterdam. Atmos Environ 2000; 34: 3713-22.

16 Roorda-Knape MC, Janssen NAH, Hartog JJ de, Harssema H, Brunekreef B. Air pollution from traffic near major motorways. Atmos Environ 1998; 32: 1921-30.

17 Krewski D, Burnett RT, Goldberg MS, et al. Reanalysis of the Harvard Six Cities study and the American Cancer Society study of particulate air pollution and mortality: a special report of the institute's particle. Epidemiology reanalysis project-final version. Cambridge, MA, USA: Health Effects Institute, 2000.

18 Nyberg F, Gustavsson P, Järup L, et al. Urban air pollution and lung cancer in Stockholm. Epidemiology 2000; 11: 487-95.

19 Babisch W, Ising H, Gallacher JEJ, Sweetnam PM, Elwood PC. Traffic noise and cardiovascular risk: the Caerphilly and Speedwell studies, third phase-10 year follow up. Arch Environ Health 1999; 54: 210-16.

20 Burnett R, Ma R, Jerrett M, et al. The spatial association between community air pollution and mortality: a new method of analyzing correlated geographic data. Environ Health Perspect 2001; 109 (suppl): 375-80.

21 Bloemen HJTh, van Bree L, Buringh E, et al. Fine particles in the Netherlands. Report 650010006. Bilthoven, Netherlands: National Institute of Public Health and Environment, 1998 (in Dutch with English summary).

22 Wallace L. Indoor particles: a review. F Air Waste Manage Assoc 1996; 46: $98-126$.

23 Rijnders E, Janssen NAH, van Vliet PHN, Brunekreef B. Personal and outdoor nitrogen dioxide concentrations in relation to degree of urbanization and traffic density. Environ Health Perspect 2001; 109 (suppl): 411-17.

24 Kuenzli N, Medina S, Kaiser R, Quenel P, Horak F, Studnicka M. Assessment of deaths attributable to air pollution: should we use risk estimates based on time series or on cohort studies? Am f Epidemiol 2001; 153: 1050-55.

25 Brunekreef B, Janssen NAH, de Hartog J, Harssema H, Knape M, van Vliet P. Air pollution from truck traffic and lung function in children living near motorways. Epidemiology 1997; 8: 298-303.

26 van Vliet P, Knape M, de Hartog J, Janssen N, Harssema H, Brunekreef $\mathrm{B}$. Motor vehicle exhaust and chronic respiratory symptoms in children living near motorways. Environ Res 1997; 74: 122-32.

27 Brunekreef B. Air pollution and life expectancy: is there a relation? Occup Environ Med 1997; 54: 781-84.

28 Künzli N, Kaiser R, Medina S, et al. Public-health impact of outdoor and traffic-related air pollution: a European assessment. Lancet 2000; 356: $795-801$.

29 van Wijnen JH, van der Zee SC. Traffic-related air pollutants: exposure of road users and populations near busy roads. Rev Environ Health 1998; 13: $1-25$.

30 WHO. Air quality guidelines for Europe, 2nd edn. Copenhagen: World Health Organization Regional Publications, European series 91, 2000.

31 Seaton A, MacNee W, Donaldson K, et al. Particulate air pollution and acute health effects. Lancet 1995; 345: 176-78.

32 Peters A, Döring A, Wichmann HE, Koenig W. Increased plasma viscosity during the 1985 air pollution episode: a link to mortality? Lancet 1997; 349: 1582-87.

33 Takano H, Yoshikawa T, Ichinose T, Miyabara Y, Imaoka K, Sagai M. Diesel exhaust particles enhance antigen-induced airway inflammation and local cytokine expression in mice. Am f Respir Crit Care Med 1997; 156: 36-42. 